\title{
OPTIMALISASI PERAN GURU DALAM PROSES PEMBELAJARAN
}

\author{
Angga Winata Harahap ${ }^{1}$, Hamidah $D^{2}$ \\ Program Studi Administrasi Pendidikan \\ Sekolah Tinggi Keguruan Dan Ilmu Pendidikan Budidaya Binjai \\ Kampus, Jl. Gaharu No. 147 Kel. Jati Makmur
}

\begin{abstract}
ABSTRAK
Optimilisasi peran guru sangat penting dalam menunjang proses pembelajaran di sekolah, guru profesional sangat dibutuhkan dalam mendorong kemajuan pendidikan di indonesia untukmenciptakan generasi-generasi penerus bangsa, melalui proses pembelajaran disekolah akan terciptamanusia-manusia dengan pola pikir yang baik.
\end{abstract}

Kata Kunci : Optimalisasi, Peran Guru, Pembelajaran

\section{PENDAHULUAN}

Pendidikan adalah usaha sadar untuk menumbuh kembangkan kemampuan dan potensi-potensi yangdimiliki oleh setiap manusia, lewat pendidikan kita belajar dari yang tidak taumenjadi tau lewat proses pembelajaran baikpendidikan informal, nonformal danformal. Negara maju bisa dilihat daripendidikan yang tersistematis, maksudnyapendidikan itu telah terencana untuk terusmenumbuh kembangkan pribadi yang lebihbaik para peserta didik untuk masa

kedepannya dan dalam jangka waktu yanglama. Dinegara maju peran guru sangat dihargai, misalnya dinegara jepang setiapguru akan dijamin kesejahteraan hidupnya,agar guru bisa secara optimal mentransferilmu yang dimilikinya terhadap pesertadidik. Lewat proses pembelajaran manusiadidorong untuk merubah pola pikir yangkritis dan inovatif untuk kemajuan suatunegara didunia.

Guru profesional adalah kunci dari majunya pendidikan di indonesia, maka 
dari itu guru dituntut terus mengembangkancakrawala berpikirnya agar lebih luasdalam menjalankan tugas, tanggung jawabdan fungsinya sebagai tenaga pengajarsupaya proses pembelajaran bisa lebihefektif dan efisien untuk menciptakangenerasi-generasi muda yang potensial dandapat bersaing oleh bangsabangsa lain diseluruh dunia.

\section{PEMBAHASAN}

Optimalisasi peran guru adalah segala sesuatu yang harus ada dalam diriseorang guru dalam meningkatkan kinerjaguru secara optimal, misalnya guru haruslebih meningkatkankemampuan

danketerampilannya dalam proses belajarmengajar agar peserta didik dalammengikuti pembelajaran lebih terbuka caraberpikirnya dan dapat menyerap materimateri yang diajarkan gurunya.

\section{PERAN GURU}

Peran guru sebagai pemberi

informasi harus bergeser menjadi manajerpembelajaran dengan sejumlah peran-perantertentu, karena guru bukan satusatunya sumber informasi melainkan hanya salahsatu sumber informasi. Dalam bukunyayang berjudul Reinventing Education,Louis V. Gerstmer, Jr., dkk. (1995), menyatakan bahwa di masa-masamendatang peran guru mengalamiperluasan, yaitu guru sebagai : pelatih(coaches), konselor, manajer pembelajaran,partisipan, pemimpin pembelajar, danpengarang (penulis).

Sebagai konselor, guru harus mampu menciptakan satu situasi interaksibelajar mengajar yang akrab sehingga siswadapat melakukan pembelajaran dalamsuasana psikologis yang kondusif tanpa adajarak atau kekakuan (rasa canggung) siswadengan guru.

Sebagai manajer pembelajaran, guru memiliki kemandirian dan otonomiyang seluas-luasnya dalam mengelolakeseluruhan kegiatan belajar mengajardengan mendinamiskan seluruh sumberpenunjang pembelajaran. Sebagai manajerpembelajaran dengan TIK guru harusmemiliki pengelolaan, pengawasan, danevaluasi yang baik. 
Sebagai partisipan, guru tidak hanya berperilaku mengajar akan tetapi jugaberperilaku belajar dari interaksinyadengan siswa. Hal ini mengandung maknabahwa guru bukanlah satu-satunya sumberbelajar, melainkan juga fasilitatorpembelajaran siswa.

Sebagai pemimpin, diharapkan guru mampu menjadi seorang yang mampumenggerakkan siswa untuk mewujudkanperilaku menuju tujuan bersama.

Sebagai pembelajar, guru harus secara terus-menerus belajar TIK dalamrangka menyegarkan kompetensinya disamping meningkatkan kualitas profesionalnya.

Sebagai pengarang (penulis), guru harus selalu kreatif dan inovatifmenghasilkan berbagai karya tulis yangakan digunakan untuk melaksanakan tugas-tugas profesionalnya.

\section{GURU PROFESIONAL}

Dengan pola rekrutmen dan

pembinaan karier guru yang baik, akantercipta guru yang profesional dan efektif.
Untuk kepentingan sekolah, memiliki guruyang profesional dan efektif merupakankunci keberhasilan bagi proses belajarmengajar di sekolah itu. John Goodlad,seorang Tokoh Pendidikan AmerikaSerikat, pernah melakukan penelitian yanghasilnya menunjukkan bahwa peran guru 
individual (bukan atas dasar KKN-pen).

3. Memiliki sistem seleksi dan sertifikasi.

4. Ada kerja sama dan kompetisi yang

sangat signifikan bagi setiap sehat antar sejawat.

keberhasilanproses pembelajaran. Penelitian itukemudian di publikasikan dengan judul"Behind the Classroom Doors", yang didalamnya dijelaskan bahwa ketika paraguru telah memasuki ruang kelas danmenutup pintu-pintu kelas itu, makakualitas pembelajaran akan lebih banyakditentukan oleh guru.

CO. Houle (1980), membuat ciriciri suatu pekerjaan disebut profesionalmeliputi :

1. Harus memiliki landasan pengetahuan yang kuat.

2. Harus berdasarkan atas kompetensi

5. Adanya kesadaran profesional yang tinggi.

6. Memiliki prinsip-prinsip etik (kode etik).

7. Memiliki sistem sanksi profesi

8. Adanya militansi individual.

9. Memiliki organisasi profesi

\section{PROSES PEMBELAJARAN}

Belajar merupakan kegiatan aktif

siswa dalam membangun makna ataupemahaman terhadap suatu konsep,sehingga dalam proses pembelajaran siswamerupakan sentral kegiatan, pelaku utama 
dan guru hanya menciptakan suasana yangdapat mendorong timbulnya motivasibelajar pada siswa.

Secara garis besar aspek-aspek yang perlu di perhatikan guru dalam merancangdan melaksanakan kegiatan pembelajaranmeliputi : pengelolaan ruang belajar(kelas), pengelolaan siswa dan pengelolaankegiatan pembelajaran (Puskur, BalitbangDepdiknas, 2002).

\section{Pengelolaan Ruang Belajar (Kelas)}

Ruang belajar merupakan tempat berlangsungnya kegiatan pembelajaran,lazimnya berbentuk ruang kelas. Ruangtersebut tentunya harus ditata sedemikianrupa sehingga kegiatan pembelajaran dapatberlangsung secara optimal. Oleh karenaitu, suasana dan penataan ruang belajarhendaknya memperhatikan paling tidakempat kondisi berikut :

a. Aksebilitas, yakni siswa maupun guru mudah menjangkau alat dan sumberbelajar yang sedang digunakan dalamproses belajar mengajar.

b. Mobilitas, yakni siswa dan guru mudah bergerak dari suatu bagian ke bagianlain dalam kelas.

c. Interaksi, yakni memudahkan perorangan,

berpasangan, ataupunkelompok secara variatif.

\section{Pengelolaan Siswa} terjadinya interaksi antara guru dansiswa maupun antar sesama siswa.

d. Variasi kerja siswa, yakni memungkinkan siswa bekerja secara 
Siswa dalam suatu kelompok kelas

$\begin{array}{lrr}\text { biasanya memiliki } & \text { kemampuan } \\ \text { yangberagam, } & \text { terutama } & \text { dalam } \\ \text { menerimasejumlah } & \text { pengalaman belajar } \\ \text { termasuk didalamnya materi yang harus } \\ \text { dikuasainya. }\end{array}$

Bobbi DePorter \&amp; Mike Hernacki

(2001 : 117 ) mengelompokkankarakteristik modalitas belajar siswa kedalam tiga karakter, yakni :

1) Pelajar visual, yakni kemampuan belajar cepat dengan menggunakanpenglihatan mata.

2) Pelajar auditorial, yakni kemampuan belajar cepat dengan pendengaran.
3) Pelajar kinestik, yakni kemampuan belajar dengan cara bergerak, bekerjaatau menyentuh, dan bahasa tubuhlainnya.

3. Pengelolaan Kegiatan Pembelajaran

Kegiatan belajar siswa perlu

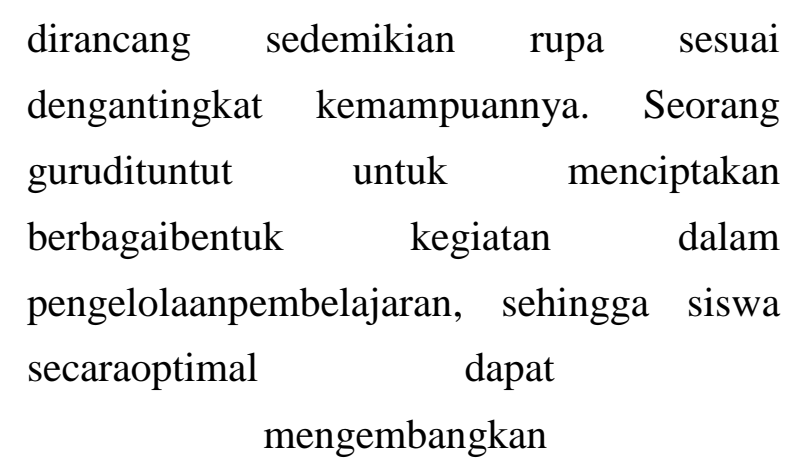

$\begin{array}{lcr}\text { kemampuan dirinya } & \begin{array}{l}\text { dengan } \\ \text { berbekalpengalaman yang di }\end{array} \\ \text { selamamelakukan kegiatan belajar. } & \end{array}$




\section{KAJIAN TEORITIS}

Dengan adanya berbagai

penemuan-penemuan yang berkaitandengan motivasi terhadap peserta didik,dalam hal ini guru berperan penting dalammemotivasi peserta didik agar lebih aktifdalam belajar disekolah.

Dr. Ovide Dicroly, yang terkenal

dengan pengajaran
"pusatminat" anak makan,
pakaian,
permaianan/bekerja. Kemudian menyusultokoh pendidikan lainnya seperti Dr. JohnDewey, yang terkenal dengan "pengajaranproyeknya", yang berdasarkan padamasalah yang menarik minat sisiwa, sistempersekolahan lainnya.

\section{Pengoptimalan peran guru untuk}

mendorong perkembangan peserta didikadalah guru juga harus mampu memberikanmotivasi terhadap peserta didik, agarpeserta didik termotivasi dalam belajar.

\begin{tabular}{llrr} 
Menurut Mc. & \multicolumn{2}{c}{ Donald } & motivasi \\
adalahperubahan & energi & dalam & diri \\
(pribadi)seseorang & yang & ditandai & dengan \\
timbulnyaperasaan & dan & reaksi & untuk \\
mencapai tujuan. & & &
\end{tabular}

$$
\text { Menurut teori multiple }
$$

tetapi juga sebagai fasilitator bagi pesertadidik dan guru sedikitnya bisa menguasaiberbagai alat media pembelajarankhususnya di bidang IT. Guru juga harusmengetahui minat dan bakat setiap pesertadidik agar kemampuan yang ada pada diripeserta didik dapat berkembang secaraoptimal.

Untuk mengoptimalkan peran guru sebagai tenaga pendidik yang profesional,guru harus memiliki berbagai kompetensididalam dirinya. Kompetensi standar guru(Depdiknas, 2001) bahwa guru harusberkepribadian utuh, berbudi luhur, jujur,dewasa, beriman, bermoral, disiplin,tanggung jawab, dan berwawasan luas.

intellegences gardner, siswa mempunyaiberbagagai intelegensi dan siswa dapatbelajar lebih baik apabila bahan disajikansesuai dengan intelegensi yang menonjolpada anak tersebut (suparno, 2004(a)). Jadi,peran guru tidak hanya dalam mengajar 


\section{KESIMPULAN}

Optimalisasi adalah hasil pencapain

sesuai yang diinginkan dari proses

dankegiatan untuk mencapai suatu tujuanbersama.

Peran guru adalah untuk menjalankan tugas, tanggung jawab danfungsinya sebagai pendidik dan fasilitatorterhadap para peserta didik.

Proses pembelajaran adalah proses kegiatan belajar mengajar yang didalamnyaada interaksi antara guru dan siswa atauproses komunikasi dan informasi timbalbalik. 


\section{DAFTAR PUSTAKA}

Anwar, Muhammad. 2018. Menjadi

Guru Profesional. Jakarta

PrenamediaGroup

Idrus, Ali. 2009. Manajemen

Pendidikan Global. Jakarta : Gp Press

Hamalik, Oemar. 2016. Proses

Belajar Mengajar. Jakarta : Pt Bumi Aksara 